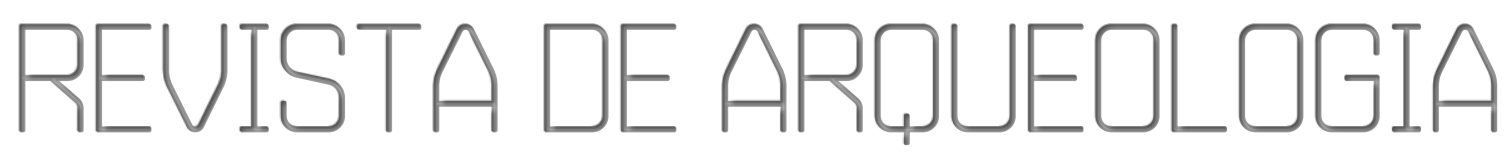

Volume 32 No. $22019 \quad$ Edição Especial: Museu Nacional [Volume 1]

\title{
O PROTAGONISMO DO MUSEU NACIONAL ENTRE A PESQUISA E A DEFESA \\ PELA PRESERVAÇÃO DO PATRIMÔNIO ARQUEOLÓGICO DE ITAIPU [NITERÓI/RJ]
}

Marcela Nogueira de Andrade*, Maria Dulce Gaspar*

RESUMO

A partir da arqueologia de Itaipu, buscamos compreender as ações de preservação do patrimônio arqueológico e das pesquisas realizadas na área. A atuação teve como protagonistas as arqueólogas do Museu Nacional, Lina Kneip e Claudia Carvalho, mas também do arqueólogo Ondemar Dias do Instituto de Arqueologia Brasileira. Por meio de documentação disposta nos arquivos do Instituto do Patrimônio Histórico e Artístico Nacional, realizamos uma abordagem histórica sobre as pesquisas nos sítios arqueológicos Duna Grande, Duna Pequena e Camboinhas, e sobre a defesa da preservação do patrimônio arqueológico de Itaipu. Concluímos que para cada sítio foi realizada uma determinada ação e que a área ainda apresenta um potencial para ser pesquisada.

Palavras-chave: Itaipu; Museu Nacional; Patrimônio Arqueológico.

\footnotetext{
* Universidade Federal do Oeste do Pará; Museu Nacional/UFRJ. E-mail: mna.arqueo@gmail.com. ORCID: https://orcid.org/0000-0001-9925-8842.

** Professora Colaboradora Voluntária PPGArq Museu Nacional/UFRJ, pesquisadora do CNPq 2015-19. E-mail: madugasparmd@gmail.com. ORCID: http://orcid.org/0000-0002-5483-4495.
} 


\section{THE PROTAGONISM OF THE MUSEU NACIONAL BETWEEN RESEARCH AND}

\section{DEFENSE FOR THE PRESERVATION OF ITAIPU'S ARCHAEOLOGICAL} HERITAGE [NITERÓI/RJ]

\section{ABSTRACT}

By Itaipu archeology we search understand the actions of heritage preservation and the researches done in the area. The performance held by the protagonist Museu Nacional's archeologist, Lina Kneip and Claudia Carvalho, but also the archeologist Ondemar Dias of Instituto de Arqueologia Brasileira. Throught the analysis of documents held by Instituto do Patrimônio Histórico e Artístico Nacional we accomplish a historical approach about the researches in the archeological sites Duna Grande, Duna Pequena and Camboinhas and the defense of the preservation Itaipu archeological heritage. We conclude that for each site was performed a particular action and that area still has a potential to be researched.

Keywords: Itaipu; Museu Nacional; Archaeological Heritage.

\section{EL PROTAGONISMO DEL MUSEU NACIONAL ENTRE LA INVESTIGACIÓN Y LA DEFENSA PARA LA PRESERVACIÓN DEL PATRIMONIO ARQUEOLÓGICO DE ITAIPU (NITERÓI/RJ)}

RESUMEN

A partir de la arqueología de Itaipu buscamos comprender las acciones de preservación del patrimonio arqueológico y de las investigaciones realizadas en el área. La actuación tuvo como protagonistas a las arqueólogas del Museu Nacional, Lina Kneip y Claudia Carvalho, pero también del arqueólogo Ondemar Dias del Instituto de Arqueología Brasileira. Por medio de documentación dispuesta en los archivos del Instituto do Patrimônio Histórico e Artístico Nacional realizamos un abordaje histórico sobre las investigaciones en el área en los sitios arqueológicos Duna Grande, Duna Pequena y Camboinhas y sobre la defensa de la preservación del patrimonio arqueológico de Itaipu. Concluimos que para cada sitio se realizo una determinada acción y que el área aún tiene potencial para ser investigada.

Palabras clave: Itaipu; Museu Nacional; Patrimonio Arqueológico. 


\section{INTRODUÇÃO}

A pesquisa arqueológica em Itaipu se relaciona intrinsicamente com a defesa da preservação do patrimônio arqueológico. As poucas pesquisas realizadas e as atuações para a preservação foram efetuadas por arqueólogos do Museu Nacional (MN), do Instituto de Arqueologia Brasileira (IAB) e por técnicos do Instituto do Patrimônio Histórico e Artístico Nacional (IPHAN).

Essas pesquisas foram consideradas como ações pontuais realizadas por três arqueólogos em momentos distintos. As denúncias e a indicação para a preservação ocorreram desde a década de 1960. A principal fonte de pesquisa foi a documentação disposta em quatro arquivos do IPHAN: Arquivo Noronha Santos (ANS); Arquivo da Assessoria de Arqueologia da Superintendência do IPHAN-RJ; Arquivo também desta Superintendência; e Museu de Arqueologia de Itaipu (MAI) ${ }^{1}$. Foram analisados 974 documentos, sendo aqui abordados apenas os que permitem formar o cenário diverso e complexo sobre a atuação dos arqueólogos, sociedade civil e IPHAN na região de Itaipu².

Apresentaremos a seguir uma abordagem teórica sobre o conceito de patrimônio e a história de Itaipu descrita pelos documentos, com o principal olhar para a atuação quase que hegemônica do MN na área nas pesquisas e luta pela preservação do patrimônio arqueológico.

\section{PRESERVAÇÃO DO PATRIMÔNIO ARQUEOLÓGICO}

Conceituações atuais sobre patrimônio histórico e bem cultural constituem uma construção lenta e gradual por parte da cultura ocidental, na qual sua sistematização ocorreu apenas na contemporaneidade. A tratativa sobre a conservação e valorização de objetos considerados como obras de arte foi realizada desde remotos tempos históricos e em diferentes períodos. A composição de coleções de arte e seleção de objetos que anteciparam a criação dos museus são atividades que ocorrem desde o século III a. C, bem como a elaboração de medidas jurídicas criadas na antiguidade romana para evitar o espólio e a destruição de obras de arte (CHOAY, 2006; GONZÁLEZ-VARAS, 2008).

A efetivação da conservação desses objetos ou dos bens culturais está amalgamada pelos sistemas culturais, políticos, econômicos, ético-religiosos, sendo necessária uma reflexão crítica que reconheça seu privilegiado valor histórico, artístico ou cultural. As mudanças que ocorreram nos fundamentos da estrutura social e ideológica, na segunda metade do século XVIII, culminaram na crítica ao passado exercida pelo Iluminismo como movimento cultural e na Revolução Francesa (ocorrida no final do século XVIII) como processo político.

Durante a Revolução Francesa, os ânimos revolucionários destruíram os marcos representativos do Antigo Regime, seus símbolos e monumentos. Nesse momento de destruição, alguns intelectuais indicaram a perda relevante que estava ocorrendo e assim "a noção de Patrimônio afirma-se em oposição ao vandalismo. Desencadeava-se uma mobilização salvacionista de obras consideradas imprescindíveis para a nação” (ABREU, 2007: 267). A novidade da Revolução foi o surgimento dos primeiros intentos institucionais para a conservação dos monumentos históricos, com a promulgação de uma série de medidas oficiais, jurídicas e técnicas.

Verifica-se que o discurso da destruição do patrimônio que representava uma classe e um poder econômico de determinado período histórico era direcionado para o povo. A

\footnotetext{
${ }^{1}$ O MAI pertenceu ao IPHAN entre os anos de 1977 e 2009, ano de reestruturação do IPHAN e da criação do Instituto Brasileiro de Museus.

2 Informações complementares em Andrade (2018).
} 
partir de uma percepção elitista, essa política de preservação estava direcionada aos bens que não representavam o povo francês, mas sim uma pequena parcela dele. Surgiu então o viés nacionalista de representação de unidade e de união, sendo o patrimônio a base para esse discurso e os monumentos históricos a amálgama à esfera da representação nacionalista. A preservação desses elementos arquitetônicos tinha uma tendência política para a união de grupos sociais culturalmente distintos e visava criar uma identidade, entendida como um projeto de nação (SANT'ANNA, 2003). Assim, Patrimônios Históricos e Artísticos Nacionais referem-se à formação e às práticas dos Estados Nacionais, momento em que surgiu, durante a Revolução Francesa, tanto a noção de patrimônio quanto de nação (FONSECA, 2005).

Os bens representativos das nações começaram a ser reconhecidos e eram compostos por bibliotecas, museus, monumentos, obras de arte e todo um acervo capaz de expressá-las e de objetificá-las (ABREU, 2007). O patrimônio nacional estava sendo construído com a materialização da memória nacional em prédios, edifícios, monumentos, e conseguiu "a proeza de estancar um tempo veloz e de referenciar os indivíduos sobre suas próprias lembranças heroicas das nações modernas e sobre suas próprias lembranças" (ABREU, 2007: 268). A associação do patrimônio nacional a um passado glorioso difundiu-se por todo o ocidente, sendo que a noção de Patrimônio Histórico e Artístico Nacional completou este movimento.

A noção de um patrimônio único, homogêneo, representativo de um povo mudou no final da Segunda Guerra Mundial. Nesse período ocorreu, nos países capitalistas desenvolvidos, um "crescente desenvolvimento de movimentos sociais em prol dos direitos civis, da emancipação feminina, do reconhecimento da diversidade em vários níveis e aspectos" (FUNARI \& PELEGRINI, 2006: 22).

A amplitude do conceito de patrimônio também teve influência do movimento relacionado à defesa do meio ambiente, pois a natureza foi entendida como parte que deveria ser incorporada a esse conceito. O resultado dessa incorporação foi a ampliação da legislação de proteção do patrimônio para o meio ambiente e para os grupos sociais e locais, no fim da década de 1950 (FUNARI \& PELEGRINI, 2006). Assim, segundo Soares, patrimônio é um

conjunto de bens materiais e imateriais, acumulados durante o tempo ou produzidos na atualidade, os quais os homens valorizam como fundamentais para a fruição da vida no momento presente e que conservam para representar a transposição entre o passado e o presente. É, ao mesmo tempo, herança, fruição e memória. É, também, principalmente para os países em desenvolvimento, uma possibilidade de sustentabilidade (SOARES, 2009: 25).

O conceito de patrimônio, conforme os contextos históricos e sociais, foi historicamente modificado, ocorrendo discussão, análise e consequente inserção de outros elementos para a sua interpretação bem como preocupação com sua proteção (ANDRADE, 2012). O patrimônio pode ser interpretado de variadas formas a partir de diversos lugares de discussão, como pelo território, pela memória, pela paisagem, pela história, pela arte etc. "Refletir sobre o patrimônio significa, igualmente, pensar nas formas sociais de culturalização do tempo, próprias a toda e qualquer sociedade humana" (GUIMARÃES, 2007: 99). Através do tempo as sociedades constroem as visões sobre passado, presente e futuro.

Assim, foi a partir desse conceito que essa pesquisa foi realizada, identificando a histórica luta da preservação do patrimônio arqueológico de Itaipu.

DUNA GRANDE: DAS PRIMEIRAS PESQUISAS À LUTA PELA SUA PRESERVAÇÃO 
O primeiro registro em Itaipu, elaborado por Ondemar Dias, resultou na identificação do sítio arqueológico Duna Grande no início da década de 1960. A descoberta está descrita em alguns documentos indicando o ano de 1962 e outros o ano de 1963. Esse sítio foi designado como Sítio Arqueológico de Itaipu, como consta na ficha de registro de pesquisa arqueológica de 11 de novembro de 1968, assinada por Lina Kneip e Maria da Conceição de Moraes Coutinho. Também teve outras denominações como Dunas de Itaipu (RJ-12), Sítio Itaipu (RJ-JC-24) e Duna Grande de Itaipu (RJ-JC-18) (DIAS JUNIOR, 1967; IPHAN/ANS, 1975; DIAS JR, 1992).

Nesse momento, Dias registrou a existência do sítio, sendo que poucos anos depois tem uma atuação mais abrangente pelo PRONAPA ${ }^{3}$. Dias e sua equipe do IAB foram os responsáveis pelas pesquisas na área do Estado da Guanabara e um setor do Estado do Rio de Janeiro, da sua capital Niterói até a cidade de Cabo Frio, entre julho de 1965 e julho de 1966 (DIAS JUNIOR, 1967).

De acordo com a perspectiva teórico-metodológica do PRONAPA, Dias definiu a fase Itaipu, que inicialmente incluía oito sítios pré-cerâmicos: três no Estado da Guanabara e cinco no Estado do Rio, dos quais três eram sambaquis. Os sítios mais característicos para o pesquisador foram as dunas da Boa Vista (RJ-4) e de Itaipu (RJ-12). Com relação à descrição, esses sítios estão assentados em dunas estáveis, com mais de quinze metros de altura, em praias de mar aberto. Em sua composição, a malacofauna não é o elemento predominante e a superfície e encostas estão cobertas de lascas de quartzo, pontas, ossos de peixe, artefatos líticos e restos de fogueiras, tendo ainda artefatos confeccionados em diabásio, gnaisse, granito e micaxisto, sendo o mais comum o "moedor percutor" (DIAS JUNIOR, 1967).

Já no terceiro ano do PRONAPA, entre 1967 e 1968, a fase Macaé foi criada sendo constituída pelos sambaquis identificados através de prospecções acrescidos dos considerados anteriormente como integrantes da fase Itaipu, que ficou restrita aos sítios sobre dunas, não tendo a malacofauna como um elemento predominante e o traço diagnóstico sendo caracterizado pelas pontas de quartzo lascadas sem retoques (DIAS JUNIOR, 1969).

Na reunião final do PRONAPA, em 1973, foi criada a tradição Itaipu, a qual "engloba os bandos que, frente às modificações climáticas após o altitermal, alteraram seus padrões econômicos, diminuindo gradualmente a dependência dos moluscos, diversificando a coleta e dando maior ênfase à pesca" (DIAS JR, 1992: 162).

A partir de novos achados, foram criadas outras fases. A tradição Itaipu passou a constituir três fases: Itaipu "A", Itaipu "B" e Potiri. A fase Itaipu "A" refere-se aos sítios de ocupações mais antigas, a Itaipu "B" aos sítios localizados nas praias de mar aberto de fixação mais recente e a Potiri aos sítios semelhantes à fase Itaipu "B", localizados no estado do Espírito Santo.

Duna Grande de Itaipu corresponde à fase Itaipu "B" que ocupa a extremidade de uma cadeia de dunas destruídas, próxima ao maciço rochoso que adentra o oceano; represa as águas de uma laguna menor, cuja barra se localiza no sopé do morro. Dias ainda informou que existia em sua extremidade Leste um pequeno sambaqui composto por conchas do gênero Anomalocardia, indicando que possivelmente a própria Duna se assente sobre este sambaqui (DIAS JR, 1992).

Duna Grande, embora tenha sido relevante para a definição de uma tradição dentro do contexto das pesquisas do PRONAPA, nunca foi escavada. Em 1975 foi apresentado

\footnotetext{
${ }^{3}$ Programa patrocinado pelo Conselho Nacional de Pesquisas e o Smithsonian Institution com colaboração do IPHAN e organizado pelo casal Betty Meggers e Clifford Evans.
} 
um projeto ${ }^{4}$ ao IPHAN solicitando a escavação do sítio, decorrente de um convênio realizado entre o IAB e a VEPLAN-RESIDÊNCIA (empresa imobiliária) para a realização de um Programa de Pesquisa Arqueológica.

O projeto não foi aprovado pelo IPHAN e resultou na oficialização de uma comissão ${ }^{5}$ para demarcação do sítio arqueológico por meio da Portaria $\mathrm{n}^{\circ}$ 02, de 26 de janeiro de 1976, visando à proteção do monumento arqueológico e sua melhor integração dentro de roteiro de turismo cultural. A demarcação foi feita pelo "Laudo de demarcação do perímetro de proteção e de operação da Duna-Grande, na praia de Itaipu, $2^{\circ}$ Distrito de Niterói-RJ”, assinado em 25 de março de 1976. Segundo Azevedo (2017) a perspectiva da preservação, através da política de turismo cultural, estava inserida dentro do plano de gestão de Renato Soeiro ${ }^{6}$.

Há inconsistência nas solicitações da VEPLAN-RESIDÊNCIA. Primeiro, a empresa se mostra atuante cobrando a preservação da Duna, seja pelo IPHAN ou por ela mesma, pois o sítio arqueológico estava sendo destruído. Segundo, a VEPLAN-RESIDÊNCIA solicita permissão ao IPHAN para providenciar a escavação de Duna Grande. Seja por falta de conhecimento dos procedimentos legais de uma pesquisa ou apenas para proteção do sítio durante as possíveis atividades de escavação, as solicitações são incoerentes devido ao objetivo real de liberar a área para o desenvolvimento do projeto de loteamento.

Em reposta à solicitação de escavação, Renato Soeiro, em 19 de abril de 1976, por meio do Ofício $n^{\circ} 1175 / 76$, se pronuncia pela proteção integral do monumento arqueológico, pela preservação ecológica típica que o integra e pelo interesse paisagístico e turístico que envolve e engloba a sua finalidade cultural. Com isso, a VEPLANRESIDÊNCIA deveria retirar o canteiro de obras da área ocupada, o que não ocorreu.

Sobre a proteção da Duna com a colocação de moirões de cimento armado e tela fina em toda a extensão, o IPHAN se manifestou para entrar em contato com seus técnicos para que juntos estudassem o melhor agenciamento. Esse cercamento não foi efetivado pela empresa, e foi colocada uma placa de identificação do sítio arqueológico Duna Grande (figura 1). Kneip denunciou que o referido sítio estava cada vez mais destruído pela erosão eólia, mas principalmente pela ação humana. Cita a instalação de barracas de camping e coleta sistemática de ossos arqueológicos e declara que apenas o cercamento completo poderia acabar com essas ações.

A demanda para o cercamento foi encaminhada para a Assessoria Jurídica do IPHAN, a qual, segundo o parecer no 4/1979 de 16 de fevereiro de 1979, concluiu que o IPHAN pode determinar normas relativas para a construção da cerca em torno do multifacetado monumento arqueológico. Kneip sugere que além da cerca deveria ser instalado um sistema de fiscalização.

Em relatório encaminhado ao IPHAN, em 25 de março de 1979, Kneip comunicou que considerava Duna Grande como o último monumento pré-histórico intacto de Itaipu, bem como de todo o município de Niterói, e informou que o mesmo estava sendo destruído paulatinamente pela natureza (ação eólia) e, principalmente, pela ação antrópica. Para Kneip, esse sítio deveria ser considerado de preservação permanente e sugeriu que a investigação prevista pelo IPHAN deveria apenas expor cortes estratigráficos preservando-os in loco, uma vez que se tratava de um monumento de importância não apenas científica como também educativa, paisagística e turística (IPHAN/ANS, 1979a).

\footnotetext{
${ }^{4}$ Em 2010 ocorreu uma ação de salvamento emergencial.

5 Composta por Edgard Jacintho e Alfredo Russins do IPHAN e Lina Kneip do MN.

${ }^{6}$ Diretor do IPHAN no período de 1967 a 1979.
} 
Figura 1 - Duna Grande, ano de 1978, com a placa de identificação, a vegetação e sem construções em seu entorno nessa parte duna (IPHAN/ANS, 1987).

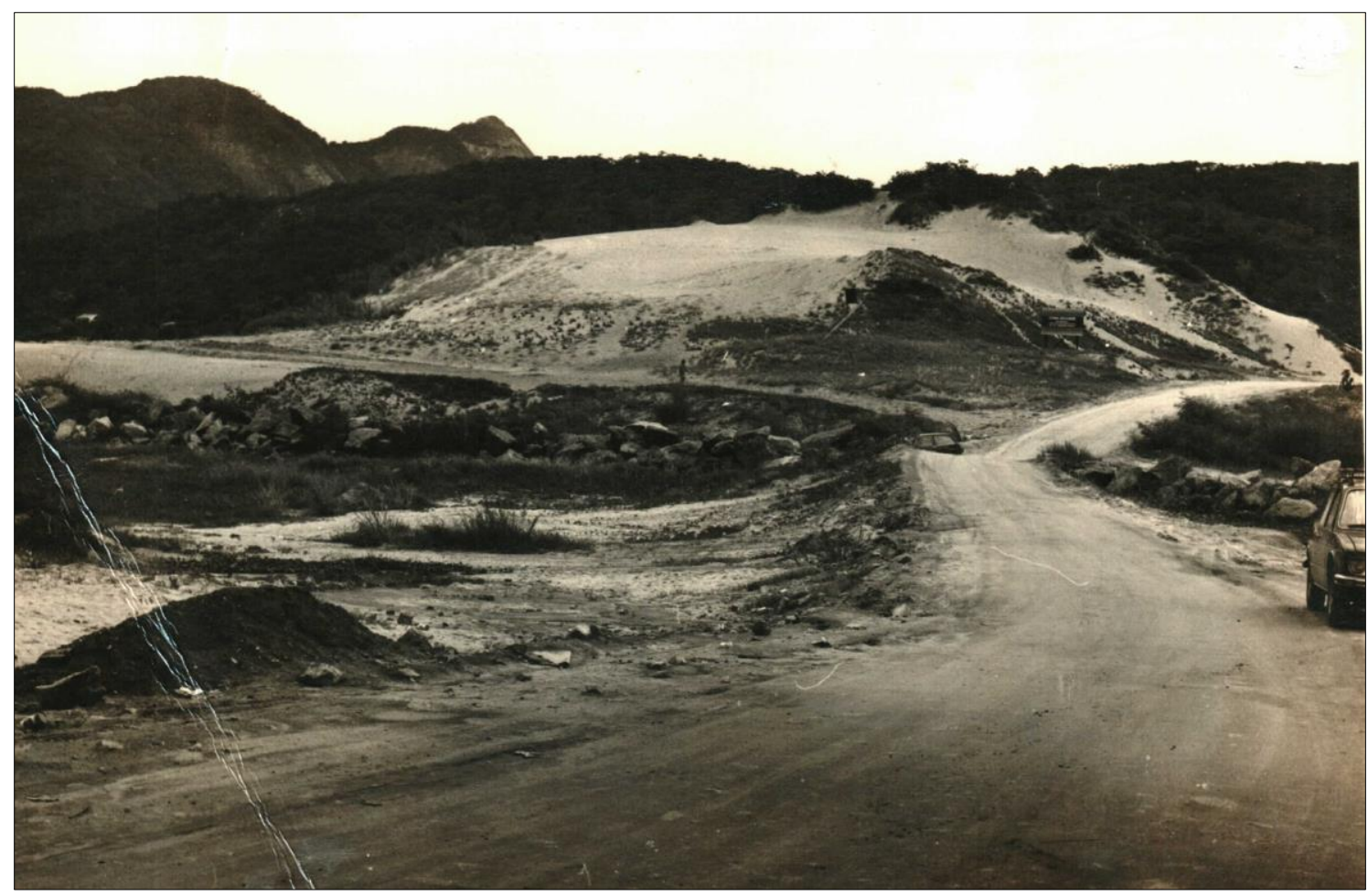

O discurso para a preservação de Duna Grande sempre foi apresentado em destaque, indicando ser o único sítio ainda existente em Niterói. Segundo a arqueóloga do IPHAN Rosana Najjar, no Parecer no 10/86/Arq, de 20 de agosto de 1986, esse único testemunho não deveria ser entregue à especulação imobiliária e que as medidas ideais para a preservação/proteção do sítio seriam: desapropriação dos lotes existentes no perímetro do sítio e cercamento imediato (IPHAN/ANS, 1986a).

Duna Grande também foi alvo de duas ações significantes, quase simultâneas, na década em 1980, visando a preservação: foi considerada monumento-símbolo da Arqueologia pré-histórica brasileira e indicada para ser tombada pelo Decreto-lei $\mathrm{n}^{\circ}$ 25/1937.

Dentro do Projeto de 50 anos do IPHAN, foi indicada a seleção de monumentosímbolo relacionada à bem tombado. O setor de Arqueologia do órgão se pronunciou, sugerindo que houvesse também um monumento-símbolo referente ao bem arqueológico, tendo sido, portanto, proposto Duna Grande.

Assim, o projeto apresentado pelo Núcleo de Arqueologia, além de elaborar o histórico e a justificativa para Duna Grande ser eleita monumento-símbolo, propõe várias providências para a preservação do sítio: tombamento pelo IPHAN; elegê-lo Monumento Símbolo da Arqueologia Pré-Histórica Nacional; efetuar o cercamento com vegetação para evitar a ação natural e predatória do homem; e impedir que a VEPLANRESIDÊNCIA realize pesquisa arqueológica pretendida. A Duna Grande foi então intitulada monumento-símbolo conforme identificado em pareceres posteriores, como observado no documento de abertura do processo de tombamento:

sabendo da suma importância que representa a preservação deste sítio para o patrimônio arqueológico nacional, ressaltamos inclusive que foi escolhido como 
Monumento Símbolo da Arqueologia Brasileira dentro das Comemorações dos 50 anos da SPHAN" (IPHAN/ANS, 1987: 6).

Esse processo teve então sua abertura a partir do Parecer no 15/86/Arq., assinado pela arqueóloga Aparecida Coelho, em 10 de dezembro de 1986, com a provocação realizada através da carta de Kneip, datada de 08 de outubro de 1986. Aparecida Coelho destacou que, mesmo com a importância de Duna Grande, expressa tanto em trabalhos publicados quanto em ações e pareceres referentes à sua preservação, esse sítio ainda estava ameaçado de total destruição.

A danificação empreendida pela natureza (eólica e da chuva) associam-se: crescente interesse imobiliário na área, as construções ilegais, usos mais arbitrários e condenáveis como subida de automotores, salto de asa delta, depósito de detritos etc., fatos que estão deteriorando e violentando o patrimônio paisagístico destruindo importantes vestígios arqueológicos que retratam a interação étnica de toda a região.

Gostaríamos de registrar que, além do trabalho de pesquisadores, há um grande interesse da comunidade em ver preservado "este bem", ressaltando entre outros o trabalho empreendido pelo Sr. Hildo de Mello Ribeiro, que com dedicação e carinho coletou por longo tempo artefatos deste sítio impedindo que se perdesse, irremediavelmente, este material que hoje se encontra em pesquisa de laboratório (IPHAN/ANS, 1986b: 3).

São diversas as ações de destruição que impactaram Duna Grande, incluindo coleta aleatória de material arqueológico, conforme identificado no referido parecer como preservação. Sob a Lei no 3924/61, essa não é considerada uma ação de preservação, mas, se for considerada a histórica relação da comunidade com a Duna, a coleta de material faz parte da relação viva entre o espaço/sítio e as pessoas.

Aparecida Coelho conclui solicitando a urgência do tombamento considerado "como único meio de preservá-lo para que as gerações futuras tomem conhecimento da luta que a SPHAN tem empreendido nestes 50 anos de existência, pela preservação do legado de nossos antepassados" (IPHAN/ANS, 1986b: 6).

Parte da documentação é composta pelo relatório de vistoria realizada em 17 de novembro de 1987 por técnicos do IPHAN, no qual consta a orientação para cercamento físico urgente. Duna Grande estava bastante comprometida pelo pisoteamento excessivo e utilização inadequada para competições de moto-cross e vôo livre, dentre outras atividades que desestabilizam a Duna tornando-a vulnerável às ações naturais do vento e da chuva.

Os técnicos estavam de acordo com a preservação, porém, antes de qualquer iniciativa de proteção da área, deveriam ser efetivadas as seguintes ações: imediata definição da poligonal de tombamento e o cercamento integral da área, já que o pisoteio, o corte de vegetação, invasões e a poluição contribuíam progressivamente para a destruição do sítio; o plantio de espécies vegetais fixadoras de dunas, como, por exemplo, Ipomea pescapreae, nas áreas mais profundamente alteradas. Indicaram que a proximidade do MAI garantiria a possibilidade de fiscalização direta sobre a área que estava em estudo de tombamento, bem como a possibilidade de visitações programadas, após o seu cercamento.

Já o último parecer que está de acordo com o tombamento é a Informação $\mathrm{n}^{\circ}$ 013/90, de 21 de fevereiro 1990, da arquiteta Marta Anastácio. Ele aborda a conclusão do processo, devido o consenso técnico para a preservação da Duna, e indica como próximas etapas: reunião técnica dentro da Instituição com a participação das Coordenadorias de Patrimônio Natural, Arqueologia, Jurídica, Proteção e 6 ${ }^{\mathrm{a}}$ Diretoria Regional - para definir se a Duna Grande seria também protegida pelo Decreto-Lei 
25/37 por meio do tombamento; e reunião técnica com os outros órgãos envolvidos, a fim de estabelecer diretrizes comuns de atuação para a preservação.

Para Ferreira (2017), o tombamento parecia ser uma decisão sensata, mas que também poderia ser interpretada como uma paralização do IPHAN "em prol da preservação da Duna Grande por meio de sua divulgação com atividades de educação patrimonial e com o estabelecimento de um itinerário de visitação para o sítio musealizado" (FERREIRA, 2017, p. 261).

Em 2014 todos os processos abertos nas situações "em estudo" e "sobrestado", que estavam no DEPAM/Rio ${ }^{7}$ e no acervo do Arquivo Central do IPHAN - Seção RJ, foram transferidos para o DEPAM localizado no Distrito Federal. Por fim, por meio do Despacho no 284/2014-PRESI/IPHAN, de 08 de setembro de 2014, a Presidente Jurema Machado arquivou o processo.

Sob outra perspectiva, foi realizado o único salvamento arqueológico em Duna Grande por uma equipe do MN, coordenada pela arqueóloga Claudia Carvalho, sendo resultado de uma ação emergencial. A pesquisa foi especificamente para uma área com exposição de uma calota craniana que resultou na evidenciação de quatro sepultamentos. Essa pesquisa relativiza a interpretação de que esse sítio arqueológico era um acampamento, como definido por Prous (1992), fazendo o contraponto sobre todas as abordagens anteriores para o contexto arqueológico de Itaipu.

Em 23 de setembro de 2010 o morador da região, Ricardo Fampa, comunicou ao MAI que havia encontrado um crânio no sítio. No mesmo dia a diretora-substituta do MAI, Vera Lúcia Gigante Carvalho, comunicou o achado à Assessoria de Arqueologia do IPHAN e enviou o Ofício no 079/2010/MAI ao superintendente do IPHAN, Carlos Fernando Andrade, informando a ocorrência.

A área de escavação teve um quadriculamento de $9 \mathrm{~m}^{2}$ com setores de $1 \mathrm{mx} 1 \mathrm{~m}$, sendo alcançada a profundidade de $1,30 \mathrm{~cm}$, sem atingir a base do sítio. Ao chegar na camada III foram evidenciados ossos humanos de quatro indivíduos sendo um adulto e três crianças, identificados, respectivamente, como Sepultamentos 1, 2a, $2 \mathrm{~b}$ e 3 (CARVALHO, 2010).

Todo material arqueológico foi inicialmente para a reserva técnica do MAI, sendo que a triagem e escavação do bloco seriam realizadas no MAI e posteriormente encaminhadas aos laboratórios de Arqueologia e Antropologia Biológica do MN, para curadoria e análise. Ao final das análises, os materiais seriam devolvidos ao MAI e, devido ao incêndio do MN ocorrido em 02 de setembro de 2018 e com a realização das atuais atividades de resgate no Museu, ainda não há indicação da recuperação desse material arqueológico.

Além da retirada de quatro enterramentos da Duna Grande durante o salvamento emergencial foram observados, em outros quadrantes da setorização, vestígios osteológicos. Porém, as quadrículas não foram escavadas, devido o intuito de ser elaborado um projeto com intenção de delimitar um provável local de enterramentos e prevendo também a recomposição da duna e sua proteção (CARVALHO, 2010).

Outro trabalho realizado em Duna Grande foi o de Pedro Heringer, que, em sua dissertação de mestrado realizada no $\mathrm{MN}$, trouxe a reflexão sobre a proteção desse sítio pelas ações do MAI. Heringer (2014) realizou uma atualização da poligonal do sítio e do topo para compreender o estado de evolução de conservação desde a sua descoberta até o ano de 2014.

A partir das dimensões de Duna Grande abordadas por Dias, Kneip e Carvalho, e do georreferenciamento realizado por Heringer (2014), esse autor mostrou que Duna

\footnotetext{
${ }^{7}$ Departamento do Patrimônio Material e Fiscalização.
} 
Grande sofreu uma degradação irrecuperável, podendo ser mensurada por uma perda volumétrica de $43000 \mathrm{~m}^{3}$, que, para além do volume, está a perda científica e cultural que são incomensuráveis.

\section{LINA KNEIP E AS PESQUISAS NA DUNA PEQUENA E NO SAMBAQUI DE CAMBOINHAS}

Kneip, após a primeira ida a Itaipu em 1968, retornou à região em 1977, para colaborar com o IPHAN na organização e abertura do "Museu de Arqueologia", que estava em fase de instalação no Remanescente do "Recolhimento de Santa Tereza" (KNEIP et al, 1981). Em 1978 Kneip localizou os sítios Duna Pequena e sambaqui de Camboinhas. Nesse ano, o litoral de Itaipu encontrava-se em fase de urbanização pela empresa VEPLAN-RESIDÊNCIA. A partir disso, houve entendimento entre o IPHAN e a empresa, para a elaboração de um projeto de salvamento para o sítio Duna Pequena e, logo após, o sambaqui de Camboinhas.

A arqueóloga, ao percorrer a praia, observou uma grande quantidade de quartzo depositada na encosta de uma duna. Constatou que a área se tratava de um sítio arqueológico parcialmente destruído pela abertura da estrada, mas que ainda havia possibilidade de pesquisa. Em 10 de setembro de 1978, Kneip registrou o sítio como Duna Pequena, em função da proximidade de Duna Grande e pelo fato de ter somente $18 \mathrm{~m}$ de altura, em contraste com os $25 \mathrm{~m}$ de Duna Grande.

Em 22 de setembro de 1978, Kneip encaminhou uma carta a Renato Sertã, diretor da VEPLAN-RESIDÊNCIA, informando o interesse do MN em efetuar pesquisa em Duna Pequena e solicitando informações sobre a data prevista para o início dos trabalhos, sobre a possibilidade de colaboração de mão-de-obra e de fornecimento de alojamento, auxílio financeiro, dentre outros (IPHAN/ANS, 1978a).

Em 16 de outubro de 1978 Renato Sertã, em resposta à carta de Kneip, confirmou a cooperação com a pesquisa. A VEPLAN-RESIDÊNCIA arcaria com alojamento e refeição para três técnicos em arqueologia e a mão-de-obra braçal para a escavação. Informou também que avisaria com antecedência de vinte dias sobre o início dos trabalhos na área e que, devido à mudança de cronograma, a obra - que estava prevista para o segundo semestre de 1979 - ocorreria no primeiro semestre (IPHAN/ANS, 1978b).

Sobre as ações efetivadas no sítio, Kneip realizou abordagem horizontal por meio de decapagem, em que as estruturas evidenciadas foram representadas pelas concentrações líticas (IPHAN/ANS, 1979a: 10). As escavações ocorreram entre janeiro e abril de 1979, sendo feita inicialmente a limpeza da área por toda a superfície, evitando as encostas íngremes de difícil contenção (KNEIP et al, 1981) bem como o levantamento planialtimétrico em curvas de níveis de $1 \mathrm{~m}$, tendo como referência o nível médio do mar.

A abordagem vertical da pesquisa foi executada através de quatro trincheiras e perfis. A abertura da trincheira 1 (T1) possibilitou localizar, sob a camada arenosa estéril, a camada arqueológica, definida entre 30 e $40 \mathrm{~cm}$ de profundidade (KNEIP et al, 1981) (figura 2).

As seções foram planejadas de acordo com as necessidades: quanto mais complexa a estratigrafia do sítio, maior a abertura de perfis. Em Duna Pequena, essa estratigrafia foi analisada como complexa e heterogênea, desta maneira foram realizados diversos perfis (KNEIP et al, 1981).

As decapagens efetuadas tinham a intensão de evidenciar o maior número de estruturas significativas possíveis, pois o plano de urbanização seria implementado por toda a área. Foram identificadas cerca de 16 decapagens na Quadrícula 1 (Q1) de $45 \mathrm{~cm}$ a $230 \mathrm{~cm}$ de profundidade (camada estéril atingida a $230 \mathrm{~cm}$ ). Observou-se a predominância 
de artefatos líticos, principalmente de quartzo, por toda a extensão na Quadrícula (Q1), e demais unidades de escavação. Esses artefatos às vezes formavam pequenas concentrações, associadas ou não a resíduos de carvão e ocre. Na parte norte foram evidenciadas restos de peixes e também a presença de "grafite" em alguns solos em Q1. Não foi encontrado material ósseo.

Figura 2 - Perfil Norte-Sul do Sítio Arqueológico Duna Pequena (KNEIP et al, 1981).

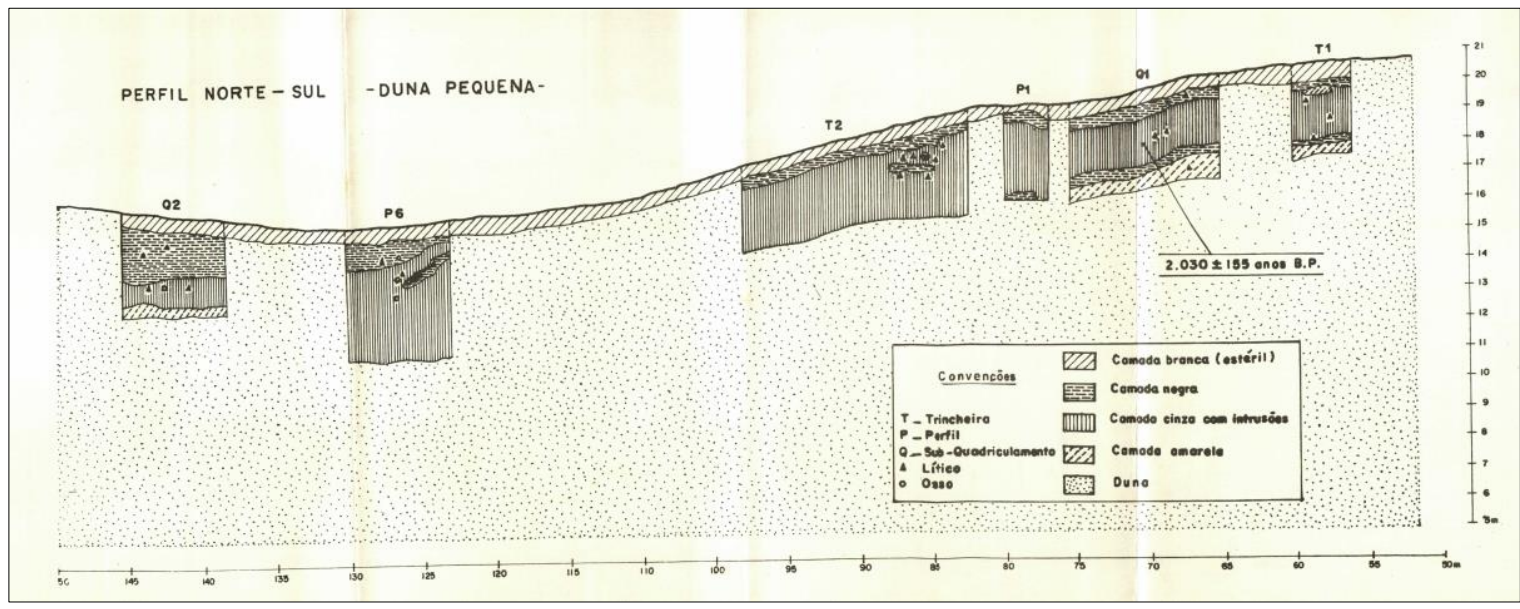

Kneip constatou a ausência de evidências de coleta de moluscos, e a "superposição das decapagens efetuadas parecem indicar épocas de grande aproveitamento e utilização da matéria-prima com áreas (...), em que o peixe era cozido ou onde se faziam as refeições" (KNEIP et al, 1981: 63).

Foram coletadas amostras de carvão em determinados níveis em Q1. Os resultados da análise, por meio do método de datação por C-14, foram de $2.030 \pm 155$ anos B.P. para a camada em $1.75 \mathrm{~m}$ de profundidade, quase no início da ocupação do sítio. Segundo Kneip, não foi possível obter resultados coerentes com as amostras de carvão coletadas em outros níveis, como na base do sítio. Houve a pretensão de encaminhar para datação amostras de restos de peixes obtidos na camada amarela, mas não foi evidenciado nenhum documento sobre o envio.

A permanência de Kneip no litoral de Itaipu tornou possível a localização do sambaqui de Camboinhas numa região de restinga entre a Praia e a Lagoa de Itaipu, a 500 metros de Duna Pequena. A observação realizada foi de que o sambaqui estava "completamente destruído" pelas obras de terraplenagem, mas ainda apresentava "camadas arqueológicas intactas".

O sambaqui de Camboinhas foi compreendido como o último da região de Itaipu, devendo portanto ser preservado. Tal preservação seria sob a forma de "blocos testemunhos" no próprio local, cercando-o e protegendo-o convenientemente, ou no laboratório sob a forma de colunas estratigráfica e porções horizontais.

Desta forma, as escavações arqueológicas de salvamento ocorreram entre julho e agosto de 1979 e de maio a agosto de 1981 (KNEIP, 1995: 83). Os objetivos das atividades eram a localização do sítio arqueológico através de trincheiras e de camadas arqueológicas intactas na área demarcada para as decapagens. Também foi realizado o levantamento planialtimétrico em curvas de níveis de $1 \mathrm{~m}$, tendo como referência o nível médio do mar.

A abordagem horizontal desenvolveu-se através de decapagem, sendo identificadas estruturas representadas por acúmulos de restos de moluscos e peixes, restos de fogueiras e artefatos diversos em pedra e osso (IPHAN/ANS, 1979b). Foram identificadas apenas 
2 decapagens (de $0-12 \mathrm{~cm}$ e $12-25 \mathrm{~cm}$ de profundidade). Já nas trincheiras, a camada estéril foi alcançada entre $50 \mathrm{~cm}$ e $1 \mathrm{~m}$ de profundidade (KNEIP et al, 1981) (FIGURA 3).

Figura 3 - Perfis estratigráficos do Sambaqui de Camboinhas (KNEIP et al, 1981).

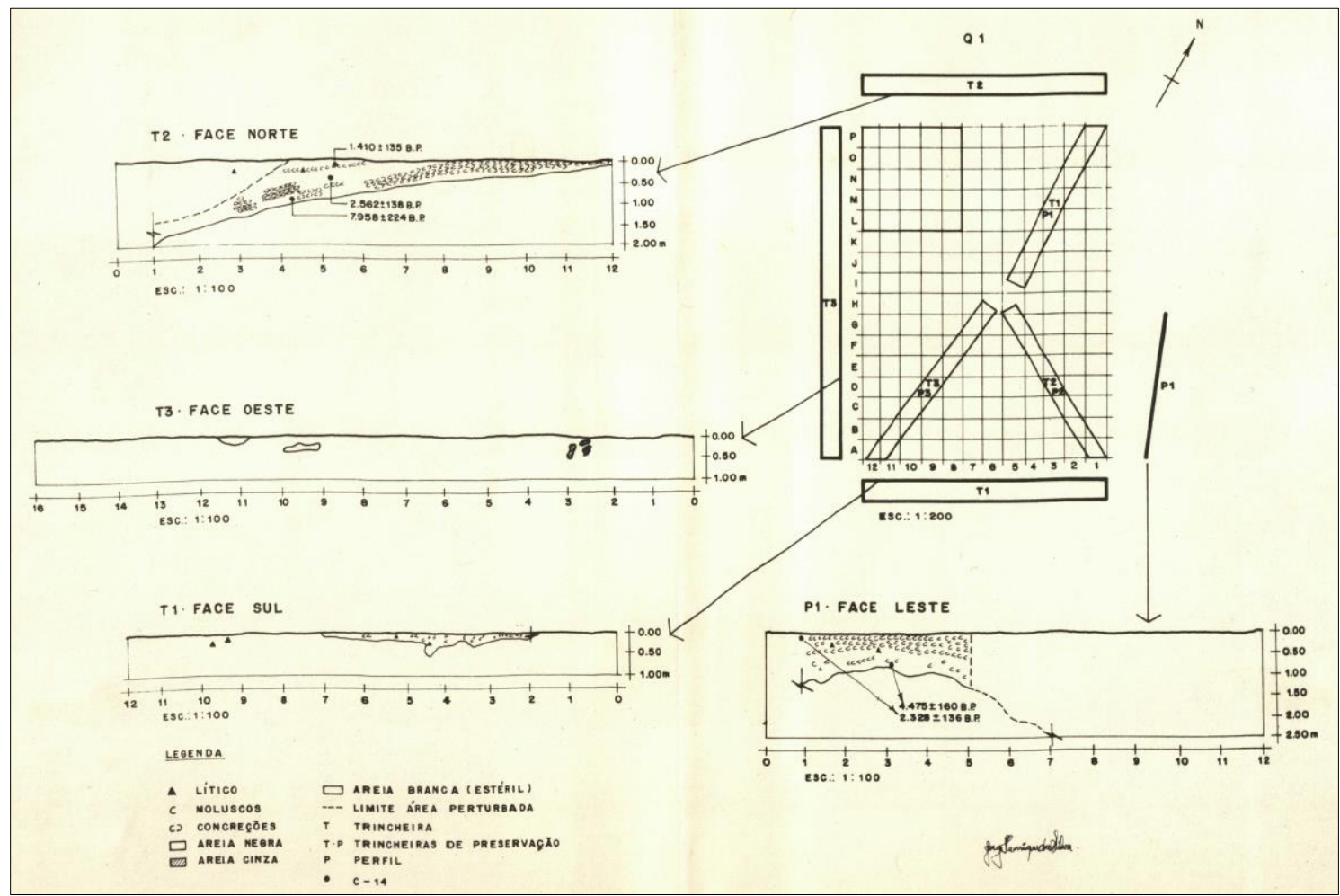

Segundo relatório encaminhado em março de 1979, a arqueóloga sugere que uma das formas de preservação pode ser feita por: 1. preservação sob a forma de "blocos testemunhos" in loco; 2 . preservação sob a forma de "blocos testemunho" em laboratório (IPHAN/ANS, 1979c).

Preservar in loco, por exemplo, implica uma solução arquitetônica a qual venha proteger e mostrar ao público vestígios significativos do ponto de vista científicocultural.

Preservar em laboratório exige também técnica especial dispensando, todavia soluções arquitetônicas. Consiste em cimentar - ou plastificar -, encaixotar e transportar para o laboratório vestígios significativos como, por exemplo, detalhes do solo arqueológico, detalhe da estratigrafia, entre outros (IPHAN/ANS, 1979c: 16).

Sobre os "blocos testemunhos", há uma descrição detalhada de todas as etapas de execução bem como sobre a técnica. No relatório de agosto de 1979, Kneip informa que foram preservados "blocos testemunhos" no laboratório do MAI de acordo com as finalidades por ela apresentadas:

1. Quatro blocos estão depositados no MAI para serem expostos pela arquiteta Maria Goulart;

2. Dois blocos estão depositados no MN (IPHAN/ANS, 1979b).

Quanto à descrição dos "blocos testemunhos" são poucas as informações. As publicações informam que foram selecionados os vestígios mais significativos a serem preservados e especifica o conteúdo apenas da primeira estrutura cimentada, que 
corresponde a uma "coluna vertebral de mamífero marinho, possivelmente de boto, associada a material lítico lascado e polido" (IPHAN/ANS, 1979b: 16). Ainda aborda que os blocos testemunhos são de "inestimável valor científico - preservar para as gerações futuras amostras significativas do sítio - tem também caráter eminentemente educativo" (IPHAN/ANS, 1979b: 24), sendo que, após protegido e artisticamente disposto, foi apresentado à opinião pública e exposto à visitação no MAI em 1979.

No relatório, Kneip informa que a direção da VEPLAN-RESIDÊNCIA verificou a possibilidade de preservar, in loco, os testemunhos restantes do sambaqui de Camboinhas. "Tal iniciativa, se concretizada, representará um acontecimento inédito na história da Arqueologia Brasileira (...). Seria, portanto, uma iniciativa sem precedentes na sequência operacional no salvamento do sambaqui de Camboinhas" (IPHAN/ANS, 1979b: 24-25).

$\mathrm{Na}$ pesquisa de Camboinhas, a abordagem vertical foi executada através de 6 trincheiras e perfis. As trincheiras foram cuidadosamente planejadas para localizar as camadas arqueológicas intactas em áreas perturbadas por aterros e para controle topográfico da área alterada pelos trabalhos de terraplenagem (KNEIP et al, 1981). Com relação aos perfis, quanto mais complexa a estratigrafia, maior a abertura de perfis. Nesse sítio, a estratigrafia se apresentou menos complexa, mas o espaço estava prejudicado pelas intrusões do aterro, segundo Lina Kneip (KNEIP et al, 1981).

Com a elaboração das decapagens em Q1, somente as estruturas aparentemente significativas foram evidenciadas, sendo representadas pelos acúmulos de restos de moluscos e peixes, testemunho da alimentação do homem, restos de fogueiras, artefatos diversos em pedra e osso, solos de coloração diversas, resíduos de carvão, ocre, matéria corante e áreas de "concreções", deixando as restantes preservadas in loco (KNEIP et al, 1981).

O sambaqui foi interpretado como "uma unidade habitacional em que grupos de indivíduos se alimentavam de quantidades de moluscos, peixes e mamíferos, utilizando implementos diversos confeccionados no local” (KNEIP et al, 1981: 63). As escavações resultaram na identificação de 1062 peças líticas e 60 artefatos ósseos de peixes e mamíferos. Para Kneip, "os pescadores, coletores e caçadores pré-históricos do sambaqui de Camboinhas tinham a subsistência mais voltada para a pesca que para a coleta de moluscos, com exceção da ocupação mais antiga" (KNEIP, 1995: 83).

Durante as escavações, foram coletadas amostras de conchas de moluscos de diferentes níveis estratigráficos para datação. Uma amostra retirada da base resultou na data de $7958 \pm 224$ anos BP, e outras amostras tiveram os resultados de: $4475 \pm 160$ anos B.P.; $2328 \pm 136$ anos BP; $2562 \pm 138$ anos BP; $1410 \pm 135$ anos BP (KNEIP et al, 1981). Esse resultado posicionou o sambaqui de Camboinhas como representante da ocupação humana mais antiga do litoral brasileiro.

Assim, Kneip ainda informa que grande parte da pré-história de Itaipu, bem como do município de Niterói, foi destruída antes mesmo de qualquer tipo de documentação fosse produzida pela ciência. As ocupações de Duna Pequena e Camboinhas foram interpretadas como representativas de integração sócio-político de bandos, sendo grupos de pescadores e coletores que se deslocavam periodicamente ao litoral de Itaipu para a pesca e coleta (animal e vegetal) e caça eventual (KNEIP et al, 1981).

Desse modo, as pesquisas de salvamento arqueológico em Itaipu realizadas em Duna Pequena e Camboinhas, e as ações para a preservação de Duna Grande, foram decorrentes das ameaças de destruição de Duna Grande e das obras de terraplenagem efetuadas no âmbito do projeto de loteamento da VEPLAN-RESIDÊNCIA. 


\section{O ENTENDIMENTO DE LINA KNEIP}

Ao analisarmos os documentos onde Kneip indica a destruição dos sítios arqueológicos, mas envia projeto para escavação dos mesmos, há um certo estranhamento. Kneip, por sua influência francesa, entendia o sítio como unidade por excelência e assim qualquer dano que o sítio tivesse sofrido era identificado como destruído.

Mesmo com essa visão, a arqueóloga, em carta de 22 de setembro de 1978, informa ser de interesse do MN elaborar pesquisa no sítio Duna Pequena, com finalidade científica e educativa-cultural que resultaria em dados sobre a paleo-ocupação e paleoambiente do litoral de Itaipu, exposição do material arqueológico no MAI e a oportunidade de a comunidade acompanhar as pesquisas.

No projeto de salvamento de Duna Pequena intitulado "Arqueologia do Litoral Fluminense - Rio de Janeiro", há a justificativa de pesquisar a área que é alvo da expansão urbana, ocasionando destruição de sítios arqueológicos. O projeto apresenta dupla finalidade:

a) Pesquisar sítios arqueológicos parcialmente destruídos ou em vias de destruição ameaçados pelo desenvolvimento urbano: pesquisas de salvamento.

b) Proteger por razões científicas e culturais os sítios arqueológicos intatos ou parcialmente destruídos preservando-os para o futuro: pesquisa de salvaguarda (IPHAN/ANS, 1979a).

Kneip faz uma diferenciação entre tipos de pesquisa, o que hoje se entende como pesquisa acadêmica e pesquisa de contrato e indica que a pesquisa a ser realizada em Duna Pequena teria como base as duas formas. Uma relevante ação da arqueóloga, dentro de uma perspectiva de pesquisa de salvaguarda/acadêmica, está para a interdisciplinaridade que envolveu especialistas das áreas da botânica, geomorfologia e zoologia da UFRJ e da USP.

A partir do conhecimento de que Duna Pequena seria totalmente destruída, reduzida a 1/3 de seu volume original, a arqueóloga solicitou permissão para pesquisá-la com a intenção de investigar a área ao máximo, devido ao possível fim imediato.

Já sobre o sambaqui de Camboinhas Kneip relata que estava completamente destruído pelas obras de terraplenagem, mas que apresentava camadas arqueológicas intactas. Concluiu que seria o último sítio tipo sambaqui da região e merecia ser preservado sob a forma de "blocos testemunhos".

Consideramos o posicionamento de Kneip para o sambaqui - que relata sua total destruição e indicando sua preservação - uma contradição. Essa oposição documentada foi a origem das dúbias interpretações sobre a existência do sítio, principalmente após a escavação e a preservação de blocos testemunhos in loco.

As escavações arqueológicas de salvamento ocorreram entre julho e agosto de 1979 e de maio a agosto de 1981 e visaram a preservação e a escavação total. A pesquisa em Camboinhas foi realizada por uma equipe interdisciplinar das áreas de arqueologia, ecologia vegetal, geomorfologia e zoologia, da UFRJ, da USP, do Museu do Homem do Sambaqui e da Fundação Estadual de Engenharia e Meio Ambiente. O Padre João Alfredo Rohr, do Museu do Homem do Sambaqui, teve participação de destaque para a preservação dos blocos testemunhos.

A pesquisa no sambaqui de Camboinhas teve como resultado a datação mais antiga do litoral do Rio de Janeiro, de $7.958 \pm 224$ anos BP, que junto com as duas datas $7803 \pm$ 1300 BP e $7327 \pm 1300$ BP, obtidas por Anette Emperaire e Joseph Emperaire para o sambaqui de Maratuá (região de Santos em São Paulo), foram duramente questionadas 
pela comunidade científica, devido a estarem fora do previsto da ocupação da costa de 6500 BP (LIMA et al, 2002).

Essas datas começaram a ser revistas e aceitas a partir da terceira evidência de antiguidade, com a datação obtida para o sambaqui do Algodão, município de Angra dos Reis no Rio de Janeiro, de $7860 \pm 80 \mathrm{BP}$, e que foram o resultado das pesquisas da arqueóloga Tânia Lima. São três ocorrências de proximidade temporal e geográfica e que recuam a cronologia tradicionalmente aceita para o assentamento da costa em pelo menos 2000 anos (LIMA et al, 2002).

O sambaqui de Camboinhas é o sítio de Itaipu que tem mais informações e diversificação de atuação. Preservado em blocos testemunho em laboratório e in loco, recuou a ocupação do litoral, teve uma atuação de equipe interdisciplinar e exposições de blocos testemunhos do MAI e no MN.

Resultados das pesquisas de Camboinhas também foram divulgados no IV Simpósio do Quaternário no Brasil, em julho de 1981, e paralelamente às pesquisas de campo foi organizada a exposição "Sambaqui de Camboinhas", em comemoração ao $163^{\circ}$ aniversário do MN.

A escavação de 1981 tinha como principal finalidade concluir os trabalhos de escavação total do sambaqui (IPHAN/ANS, 1981). Entretanto no relatório não há a indicação do sítio ter sido totalmente escavado e, caso tenha permanecido algum bloco testemunho in loco, não foram apresentadas recomendações sobre a preservação.

A confirmação dessas evidências se apresenta, por exemplo, nas documentações de 20 de julho de 1991, nas quais a própria Kneip indica a existência dos remanescentes do sambaqui de Camboinhas. Essa indicação resultou na vistoria de Lina Kneip e Rosana Najjar, no início da década de 1990, quando identificaram os remanescentes, e em 16 de março de 1992, quando solicitaram o cercamento imediato do local bem como a exposição adequada.

Como resposta à solicitação de informação sobre a existência de Camboinhas, realizada pelo vereador Renê Barreto, de Niterói, Rosana Najjar comunica, em 10 de abril de 2002, que na ficha de registro do sítio há a informação de destruição do mesmo em 1979. Já o memorando/DITEC/6aSR no 442/04, de 30 de setembro de 2004, (referente à análise do Relatório/Estudo de Impacto de Vizinhança de empreendimento imobiliário situado na Av. Beira-mar, Camboinhas - Niterói/RJ), recomenda medidas mitigadoras/compensatórias para o sambaqui de Camboinhas: arcar com as despesas do Projeto de Prospecção Arqueológica, objetivando dirimir quaisquer dúvidas quanto a permanência de bloco testemunho no local.

Destacamos ainda que, em 23 de setembro de 2004, o Conselho Comunitário da Região Oceânica de Niterói apresentou denúncias de crime ambiental e patrimonial, dentre elas a construção de prédio de seis andares em cima de parte do sambaqui de Camboinhas - caminhões com aterro e máquinas construíram uma rua exatamente em cima do sambaqui.

Foi desenvolvido um estudo, datado de março de 2004, pela empresa Theetek Soluções em Geomática Ltda, encomendado pelo Ministério Público, que resultou no Relatório do mapeamento das margens da Lagoa de Itaipu e análise preliminar de impactos sobre os ecossistemas locais, Orlas Oeste e Sul. Sobre Camboinhas, identificou que foram deixados blocos testemunhos para preservação in situ, que deveriam ser demarcados e preservados. Essa medida foi negligenciada, resultando na construção de um prédio possivelmente sobre parte do sambaqui Camboinhas entre 2002 e 2003 (IPHAN/SE-RJ, 2004). 


\section{CONSIDERAÇÕES FINAIS}

A presença dos arqueólogos em Itaipu resultou na identificação de três sítios nas décadas de 1960 e 1970. Registros, escavações, preservação de blocos testemunhos e defesa do patrimônio foram algumas das ações. Itaipu sempre foi considerada uma área interessante sob o olhar arqueológico e com afeto pelos que atuaram na área. No entanto, apesar de décadas de atuação, as informações científicas sobre o contexto arqueológico são limitadas. A pesquisa mais recente, realizada pela arqueóloga Claudia Carvalho, trouxe uma nova perspectiva para a região, colocando em discussão a identificação de Duna Grande, por André Prous, como sítio acampamento.

A intenção de Carvalho é a de realizar novas escavações, o que consideramos de suma relevância para avançar na discussão do processo de ocupação de Itaipu, destacando ainda que, apesar da dificuldade de escavar em sítio sobre duna, é possível realizar a pesquisa. Entendemos que esse projeto poderia também inserir ações pontuais em Duna Pequena e no sambaqui de Camboinhas, para acabar com qualquer dúvida sobre existência de contextos arqueológicos in situ.

Foram décadas de atuação em Itaipu que tiveram ações diferentes para cada sítio. Duna Grande, apesar dos vários danos, foi preservada decorrente da intensa luta pela sua preservação realizada pelos arqueólogos e pelo IPHAN. Já os sítios Duna Pequena e Camboinhas foram escavados, entretanto torna-se necessário ainda verificar se existe material arqueológico em contexto.

O MN teve protagonismo nas pesquisas na área pelas atuações das arqueólogas Lina Kneip e Claudia Carvalho. Apesar do material arqueológico que estava no MN provavelmente ter sido atingido pelo fogo devido ao incêndio do $\mathrm{MN}$, novas pesquisas podem ser realizadas para suscitar ainda mais a discussão sobre a ocupação antiga de Itaipu.

\section{AGRADECIMENTOS}

Ao Museu Nacional, pela sua histórica tradição na produção de conhecimento, pela atual luta e resistência. 


\section{REFERÊNCIAS BIBLIOGRÁFICAS}

ABREU, Regina. 2007. Patrimônio Cultural: tensões e disputas no contexto de uma nova ordem discursiva. In: LIMA FILHO, M. F.; BELTRÃO, J. F.; ECKERT, C. (Orgs.). Antropologia e Patrimônio Cultural: diálogos e desafios contemporâneos. Blumenau, Nova Letra, pp. 263-285.

ANDRADE, Marcela N. 2012. Conservação Integrada do Patrimônio Arqueológico: uma alternativa para o Parque Estadual Monte Alegre - Pará - Brasil. 2012. 230f. Dissertação de Mestrado. Teresina, Universidade Federal do Piauí. 230pp.

ANDRADE, Marcela N. 2018. Os olhares sobre o Patrimônio Arqueológico de Itaipu (Niterói/RJ) e sua ressignificação como Paisagem Cultural. Tese de Doutorado. Rio de Janeiro, Universidade Federal do Rio de Janeiro. 287pp.

AZEVEDO, Paulo Ormindo de. 2017. Patrimônio Cultural e Natural como fator de desenvolvimento: a revolução silenciosa de Renato Soeiro, 1967-1979. In: SCHLEE, Andrey Rosenthal (Org.). Revista do Patrimônio Histórico e Artístico Nacional, Iphan 1937-2017, Brasília, 35: 45-63.

CARVALHO, Claudia Rodrigues. 2010. Relatório preliminar Salvamento de restos esqueléticos humanos no sítio Duna Grande - Itaipu - Niterói - Rio de Janeiro. Rio de Janeiro, Museu Nacional, pp. 15.

CHOAY, Françoise. 2006. A alegoria do patrimônio. São Paulo, Estação Liberdade, UNESP. 282pp.

DIAS JUNIOR, Ondemar Ferreira. 1967. Notas sobre pesquisas arqueológicas no Estado da Guanabara e do Rio de Janeiro. Publicações avulsas. Museu Paraense Emílio Goeldi, Belém, 6: 89101.

DIAS JUNIOR, Ondemar Ferreira. 1969. Resultados preliminares do segundo ano de pesquisas no estado do Rio de Janeiro. In: Programa Nacional de Pesquisas Arqueológicas 2. Resultados preliminares do segundo ano 1966-1967. Publicações avulsas, Museu Paraense Emílio Goeldi, Belém,10.

DIAS, JR. Ondemar Ferreira. 1992. A tradição Itaipu, costa central do Brasil. In: MEGGERS, Betty (Ed.) Prehistoria Sudamerica. Nuevas perspectivas. Washington.

FERREIRA, M. S. 2017. Percursos da memória: Narrativas sobre patrimônio no Museu de Arqueologia de Itaipu. Tese de Doutorado. Rio de Janeiro, Pontifícia Universidade Católica. 328pp.

FONSECA, Maria Cecília Londres. 2005. O Patrimônio em Processo: trajetória da política federal de preservação no Brasil. Rio de Janeiro, Editora UFRJ, MinC - IPHAN. 296pp.

FUNARI, Pedro Paulo; PELEGRINI, Sandra de Cássia Araújo. 2006. Patrimônio histórico e cultural. Rio de Janeiro, Jorge Zahar Ed. 72pp.

GONZÁLEZ-VARAS, Ignacio. 2008. Conservación de Bienes Culturales. Madri, Ed. Cátedra. 628pp.

GUIMARÃES, Manoel Luiz Salgado. 2007. História, memória e patrimônio. In: CHUVA, M (Org.). História e Patrimônio. Revista do Patrimônio Histórico e Artístico Nacional, n. 34: 91-111.

HERINGER, Pedro C. S. 2014. Museu como ferramenta de proteção a sítios arqueológicos: o caso do Sítio Arqueológico Duna Grande e o Museu de Arqueologia de Itaipu. Dissertação de Mestrado. Rio de Janeiro, Universidade Federal do Rio de Janeiro. 128pp.

IPHAN/ANS. 1975. Ofício 3/75 DP Itaipu. Projeto de Pesquisa em Itaipu. Série Arqueologia, Subsérie Projetos e Relatórios. Caixa 35, Pasta 149.

IPHAN/ANS. 1978a.Conforme entendimentos verbais mantidos. Série Arqueologia, Subsérie Projetos e Relatórios. Caixa 35, Pasta 149.

IPHAN/ANS. 1978b. ST-009/78. Em 19 de outubro de 1978. Série Arqueologia, Subsérie Projetos e Relatórios. Caixa 35, Pasta 149. 
IPHAN/ANS. 1979a. Projeto Duna Pequena. Série Arqueologia, Subsérie Projetos e Relatórios. Caixa 35.

IPHAN/ANS. 1979b. Salvamento de sítios arqueológicos em Itaipu, Niterói, Rio de Janeiro - Relatório Científico. Série Arqueologia, Subsérie Projetos e Relatórios, Caixa 35, Pasta 149.

IPHAN/ANS. 1979c. Relatório referente a pesquisas em andamento em Itaipu, Niterói, Rio de Janeiro. Série Arqueologia, Subsérie Projetos e Relatórios, Caixa 35, Pasta 149.

IPHAN/ANS. 1981. Relatório referente às pesquisas arqueológicas realizadas no sambaqui de Camboinhas, Itaipu, Niterói, estado do Rio de Janeiro, durante os meses de maio, junho e julho de 1981. Série Arqueologia, Subsérie Projetos e Relatórios, Caixa 35, Pasta 152.

IPHAN/ANS. 1986a. Parecer no 10/86/Arq, de 20 de agosto de 1986. Série Arqueologia, Subsérie Administração, Caixa 129, Pasta 48.

IPHAN/ANS. 1986b. Parecer no 15/86. Série Tombamento.

IPHAN/ANS. 1987. Processo n 1.216-T-87. Série Tombamento.

IPHAN/SE-RJ. 2004. Relatório do mapeamento das margens da Lagoa de Itaipu (Niterói) e análise preliminar de impactos sobre os ecossistemas locais. Theetek Soluções em Geomática Ltda. Área Arqueologia, Pasta Duna Grande.

KNEIP, Lina Maria; PALLESTRINI, Luciana.; MORAIS, José Luiz de; CUNHA, Fausto Luiz de. 1981.The Radiocarbon Dating of the "Sambaqui de Camboinhas" - Itaipu, Niterói, RJ, Brazil. Acad. Ciênc., 53, 2.

KNEIP, Lina Maria. 1995. Documento de Trabalho $n^{\circ}$ 3. Série Arqueologia. Departamento de Antropologia - Museu Nacional. Universidade Federal do Rio de Janeiro, pp.83-102.

LIMA, Tania Andrade; MACARIO, Kita; ANJOS, Roberto Meigikos; GOMES, Paulo Roberto Silveira; COIMBA, Melayne Martins; ELMORE, David. 2002. The antiquity of the prehistoric settlement of the central-south brazilian coast. Radiocarbon, 44, 3: 733-738.

PROUS, André. 1992. Arqueologia Brasileira. Brasília. Brasília, Editora UNB. 613pp.

SANT'ANNA, Marcia. 2003. A Face imaterial do patrimônio cultural: os novos instrumentos de reconhecimento e valorização. In: ABREU, R.; CHAGAS, M. (Orgs.). Memória e patrimônio: ensaios contemporâneos. Rio de Janeiro, DP\&A, pp. 46-55.

SOARES, Inês Virgínea Prado. 2009. Direito ao (do) patrimônio cultural brasileiro. Belo Horizonte, Fórum. 478pp. 